\title{
Prevalence and Associated Factors of Low Back Pain Among Teachers Working at Governmental Primary Schools in Addis Ababa, Ethiopia: A Cross Sectional Study
}

\author{
Tsega-Ab Abebaw*1, Mitslal Kidane Weldegebriel ${ }^{2}$, Bereket Gebremichael ${ }^{3}$ and Admas Abera Abaerei ${ }^{4}$ \\ ${ }^{1}$ School of Medicine, Adama Hospital Medical College, Ethiopia \\ ${ }^{2}$ Department of Physiotherapy, Brook Hospital, Ethiopia \\ ${ }^{3}$ College of Medicine and Health Sciences, Addis Ababa University, Ethiopia \\ ${ }^{4}$ College of Health and Medical Sciences, Haramaya University, Ethiopia
}

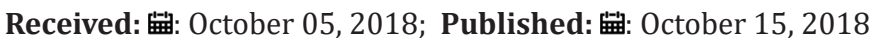

*Corresponding author: Tsega Ab Abebaw, School of Medicine, Adama Hospital Medical College, Adama, P. Box 13386 Addis Ababa, Ethiopia

\begin{abstract}
Authorship
MK participated in the conception and design of the study and coordinated the data collection. TA critically reviewed the proposal, did the data analysis, the write up and prepared the manuscript for publication. BG and AA contributed by critically reviewing the proposal, design of the study,
\end{abstract} and data analysis. All authors read and approved the final manuscript.

Abstract

Introduction: Low back pain (LBP) is among the greatest public health threats that individuals face around the world. Teachers are recognized to denote an occupational cluster in which it appears to partake a great prevalence of LBP. Nevertheless, data about its extent and associated factors among school teachers is limited in Ethiopia. Therefore, the objective of this study was to assess the prevalence and associated factors of LBP among teachers working at governmental primary schools in Addis Ababa, Ethiopia, 2016.

Materials and Methods: A school centered cross sectional study was conducted. The total number teachers participated in the study was 827 . A self-administered questionnaire was used. Bivariate and multivariable logistic regression analyses were employed to assess the outcome of different factors on LBP. A statistical significance was assumed when, P value $\leq 0.05$ at $95 \% \mathrm{CI}$.

Results: The prevalence of LBP was found to be 340 (44\%). The multivariable logistic regression showed that, ergonomics training, enough teachers in school, prolonged sitting posture and poor work place social environment were significantly associated with LBP $(A O R=2.246,3.786$, 0.237 and 6.799 respectively). Those respondents who are female, aged $30-40$ and aged $>40$ also showed a significant association $(A O R=1.547,1.96$, 4.895 respectively).

Conclusion: LBP is a thoughtful problem among governmental primary school teachers in Addis Ababa. Work place social environment, work posture, enough teachers in the school and ergonomic training are among the factors which have to be given a great attention in order to surmount the situation.

Keywords: Low Back Pain; School Teachers; Musculoskeletal Disorder

\section{Introduction}

Low back pain (LBP) is among the greatest public health threats that individuals face around the world. It is a pain at the lower part of the back and is one of musculoskeletal disorders and discomfort, localized between the coastal margin (bottom of ribs) and above the inferior gluteal folds (top of legs), with or without related leg pain from any cause [1]. LBP produces a considerable personal, community, and financial burden [2] and it is the most common reason for medical consultations globally [1]. It does not only suggest poor quality of individuals' life, but also showed decreased in labor productivity due to off-work absenteeism and early retirement [3]. According to the 2010 Global Burden of Disease Study, it was appraised that low back pain exists among the top ten diseases and injuries accounting for the uppermost number of the disability-adjusted life years globally. The World Health Organization (WHO) also identified it as one of the topmost three work-related health problems to be considered by surveillance [4]. 
It is also known to be a well-documented extremely common health problem [5]. Even though its burden is often considered trivial [6], LBP remained the leading cause of activity limitation and work absence throughout much of the world [7] causing an enormous economic burden on industry and governments [8]. Globally the annual prevalence of back pain is 31\% [9]. The oneyear prevalence of LBP among Western societies was reported to be between $20 \%$ and $62 \%$ and in Africans ranged from $14 \%$ to $72 \%$ [6]. The prevalence of LBP among teachers in Gondar was $57.5 \%$ [10]. As a result, LBP is widely acknowledged as an important health and socio-economic problem which plagues a large segment of the population in industrialized countries [11] and reportedly even worse in developing countries, with suboptimal working conditions and lack of awareness of ergonomics issues, education and training programs [12]. The work responsibilities of school teachers often involved significant use of a 'head down' posture, such as frequent reading, marking of assignments, and writing on a blackboard.

These doings involve sustained mechanical load and constant trunk flexion. Therefore, teachers have been found to have elevated prevalence of low back disorders [13]. It has been estimated that occupational exposures accounted for $37 \%$ of the global burden of disease from LBP [14] and school teachers are known to represent an occupational group among which there appears to be a high prevalence of LBP [15]. According to a cross sectional study on the working conditions and health of teachers of the municipal teaching network of Salvador, Bahia, Brazil indicated that the prevalence of LBP among teachers was $41.1 \%$. The pain in the teachers was higher among women than men [3]. Another study from Malaysia showed the prevalence of LBP among teacher respondents to be $40.4 \%$ and more than half of the respondents (56.9\%) were in service for more than 10 years [2]. A similar study in Botswana revealed, the 12-month prevalence of LBP was 55.7\%. Female gender and previous back injury were positively associated with LBP. Awkward arm position and high psychological job demands also showed a positive association while, regular physical exercise showed a negative association [15].

A study in Gondar showed that, 346 (57.5\%) of respondents experienced LBP throughout their job career. From the total respondents with LBP 116 (33.5\%) were felt the pain during standing. The prevalence of LBP was higher among female (75.9\%) than male teachers (48.9\%). More than half, 312 (51.8\%) of the respondents had work experience of above 10 years. Almost all of the respondents 589 (97.8\%) had standing position during their work (teaching) [10]. Most research has attempted to determine causal factors to predict and prevent LBP. Common factors included sex, age, work postures, and type of work [16]. There are also evidences showing that there is an association between LBP and many other factors like: negative affectivity, low levels of social support in the workplace, low level of job control, stressful responsibility, mental stress at work, negative body image, high psychological demands, job dissatisfaction, anxiety and depression [17]. Considering the factors, the main route to prevention of low back pain is likely to lie in improved ergonomics and psychological health in work place [18].
Teacher's health has a significant impact on national development since they are valuable resource for socio economic and cultural development of a country and play a great role in addressing problems like improving education that undermine health. A rising occurrence of LBP among teachers will lead to a major increase of problem and burden on the education system of a country. Even though numerous studies have investigated LBP in teachers of other countries, there is limited information available for the prevalence and contributing factors of LBP among teachers in Addis Ababa, Ethiopia. So this study will contribute for the knowledge of prevalence and associated factors of LBP among teachers working at primary governmental schools in Addis Ababa, Ethiopia. It will give a valuable input for health care planners, practitioners and school administrators for their goal of promoting health, prevention of diseases and improving quality of life.

\section{Materials and Methods}

\section{Study Design}

A school centered cross sectional study was conducted.

\section{Study Area and Period}

Addis Ababa is the city where the study was conducted. It is the capital city of Ethiopia having 10 sub cities with 214 governmental primary schools and 10,382 teachers. Total population of the city is about 3.385 million (2007). The city is also known for being the political capital of Africa. The study period was from March 31 to April 10, 2016.

\section{Source and Study Population}

All teachers working at governmental primary schools in Addis Ababa during the study period was the source population and those who were selected by using cluster sampling technique were the study population.

\section{Sample Size}

Sample size was determined using a single population proportion formula which is stated as, $\mathrm{n}=\mathrm{Z} 2 \mathrm{Pq} / \mathrm{d} 2$ (n representing the looked-for sample size and $\mathrm{Z}$, the value of standard normal variable at $95 \%$ confidence interval. The proportion of low back pain among teachers is designated by $\mathrm{p}$ and $\mathrm{d}$ is marginal error which is 5\%). According to a study conducted in Gondar, the prevalence of low back pain was assumed to be $57.5 \%$ [10]. With adding a $10 \%$ non-response rate and a design effect of 2 , the last sample size was designed to be 827 .

\section{Sampling Procedure}

Among the ten sub cities found in Addis Ababa, Arada sub-city was selected by using a lottery method. Then, the samples (827 teachers) were taken from the total teachers' population (888) from all (twenty-two) primary schools of the selected cluster using a simple random sampling technique.

\section{Inclusion and Exclusion Criteria}

Inclusion criteria: Teachers working at all governmental primary schools in Addis Ababa city during the data collection period were nominees of the study. 
Exclusion Criteria: Teachers who had an injury to the back and those who had a congenital musculoskeletal disorder like scoliosis were left out.

\section{Variables}

\section{Dependent Variable: Low back pain.}

Independent Variables: Age, sex, year of professional experience, habit of physical exercise, paid activity other than teaching, work place social environment, job satisfaction, work posture, enough teachers in the school, Previous training in ergonomics and use of teaching aid devices than chalk and board.

\section{Operational Definitions}

LBP: A teacher was considered as having a low back pain if he/ she had a perceived ache, pain or discomfort localized below the coastal margin and above the inferior gluteal fold during the last 12 months.

Professional Work Experience: Length of employment as a teacher was considered.

Habit of Doing Physical Exercise: It was considered as present when a teacher had a planned, structured and repetitive physical activity which is done at least 150 minutes of moderate aerobic activity or 75 minutes of vigorous aerobic activity a week, or a combination of moderate and vigorous activity.

Work Place Social Environment: Perceived cooperation and healthy relationship with colleagues was considered as a good social environment and the opposite as poor while neither good, nor poor was considered as fair.

Job Satisfaction: It was considered as good if the teacher likes his/her job and poor if the satisfaction was not good.

Work Posture: 'prolonged standing' and 'prolonged sitting' was defined as the working condition in which a teacher continue to assume standing working posture for over $50 \%$ of total working hours during a full work shift.

Enough Teachers in the School: It was considered as enough when the schools meet their plan for number of teachers for the subject matter taught by the teachers interviewed.

\section{Data Collection Procedures}

Data was collected using a structured, self-administered and pretested questionnaire.

\section{Quality Assurance}

The Nordic musculoskeletal inquiry form was used as a model. A modification to the form was made founded on studies which comprised the factors associated with LBP. The questionnaire was originally set in English, and translated to Amharic. In order to check for the consistency, it was again back to English by another individual. A pre-test was conducted on $5 \%$ of the sample size using the Amharic version questionnaire. It was done in schools outside of the selected cluster. Grounded on the pretest, the questions were reviewed prior to the study. Two data collectors and a supervisor were trained for a day about the data collection methods. All had a physical therapy back ground. The principal investigator of the study was supervising throughout the time.

\section{Data Management and Data Analysis}

The data was checked for completeness and consistencies, and then it was cleaned, coded and entered using Epi Info version 7. Then, it was exported to SPSS version 21 for analysis. Mean, standard deviation and proportion were used to describe the study population in relation to the relevant variable. Bivariate logistic regression model for first events were used to study the association between occurrences of LBP and different variables. Then, variables that had a $\mathrm{p}$ value of less than 0.2 in the bivariate analyses were taken in to the multivariable logistic regression model to identify independent effect of different factors on the occurrence of LBP. Statistical significance was declared when $\mathrm{P}<0.05$ at $95 \%$ CI. Finally, the result was presented in the form of text and tables.

\section{Ethical Considerations}

To conduct the study, an ethical clearance was obtained from the Ethical review committee of Addis Ababa Educational Bureau. A supporting letter was attained from Arada sub-city and the corresponding schools. Finally, a written informed consent was obtained from each study participants. The purpose and importance of the study was explained to the participants and those teachers who might refuse to participate in the study were not forced. Confidentiality was granted for information to be collected from each study participants.

\section{Results}

The total number of respondents was 771 . This makes the response rate $93.2 \%$.

\section{Socio Demographic Characteristics}

The median age of the respondents was 33 years with a SD of 10.631 with a range of 38 years (range 21-59 years). Among the respondents, 304 (39.4\%) were in the age group of 21-29 years. The sex of respondents was almost in a 1:1 ratio. Of the respondents, $413(53.6 \%)$ had $<10$ years of professional work experience (Table 1).

Table 1: Socio demographic characteristics of teachers working at governmental primary schools in Addis Ababa, Ethiopia, March 31, 2016 to April 10, 2016 (N=771).

\begin{tabular}{|c|c|c|c|}
\hline Variables & Category & Number(n) & Percent (\%) \\
\hline \multirow{2}{*}{ Sex } & Male & 393 & 51 \\
\cline { 2 - 4 } & Female & 378 & 49 \\
\hline \multirow{3}{*}{ Age Group } & $<30$ & 304 & 39.5 \\
\cline { 2 - 4 } & $31-40$ & 230 & 29.8 \\
\cline { 2 - 4 } & $41-59$ & 237 & 30.7 \\
\hline \multirow{3}{*}{ Year of Professional } & $<10$ & 413 & 51.6 \\
\cline { 2 - 4 } Experience & $11-25$ & 277 & 37.9 \\
\cline { 2 - 4 } & $26-45$ & 81 & 10.5 \\
\hline Total & & $\mathbf{7 7 1}$ & $\mathbf{1 0 0}$ \\
\hline
\end{tabular}




\section{Prevalence of Low Back Pain}

The prevalence of low back pain among the 771 study participants was found to be 340 (44\%).

\section{Factors Associated with Low Back Pain}

The binary logistic regressions model was applied to see for an association between the dependent variable and every independent variable. According to the finding, age, sex, professional work experience, habit of doing physical exercise, work place social environment, job satisfaction, work posture, enough teachers in the school, use of teaching aid devices and ergonomics training had an association with LBP. In order to look for confounding factors, multivariable logistic regression analysis was employed. According to this analysis, only six variables were found to be significantly associated with LBP: age, sex, work place social environment, work posture, enough teachers in the school and ergonomic training. Other variables like use of teaching aid devices, job satisfaction, habit of doing physical exercise and professional work experience lost their association during the multivariable logistic regression model (Table 2).

Table 2: Association of variables with low back pain among teachers working at governmental primary schools in Addis Ababa, Ethiopia, March 31, 2016 to April 10, 2016 (N=771).

\begin{tabular}{|c|c|c|c|c|c|}
\hline \multirow{2}{*}{ Variables } & \multirow{2}{*}{ Categories } & \multicolumn{2}{|c|}{ Low back pain } & \multirow{2}{*}{$\begin{array}{c}\text { COR } \\
(95 \% \mathrm{CI})\end{array}$} & \multirow{2}{*}{$\begin{array}{c}\text { AOR } \\
(95 \% \mathrm{CI}) \\
\end{array}$} \\
\hline & & Yes & No & & \\
\hline \multirow{2}{*}{ Sex } & Male & 148 & 245 & 1 & 1 \\
\hline & Female & 192 & 186 & $1.709(1.283,2.277)$ & $1.547(1.037,2.308)$ \\
\hline \multirow{3}{*}{ Age } & $<30$ & 78 & 226 & 1 & 1 \\
\hline & $30-40$ & 98 & 132 & $2.151(1.491,3.104)$ & $1.960(1.119,3.436)$ \\
\hline & $>40$ & 164 & 73 & $6.509(4.464,9.492)$ & $4.895(2.215,10.82)$ \\
\hline \multirow{3}{*}{$\begin{array}{c}\text { Year of } \\
\text { professional } \\
\text { experience }\end{array}$} & $1-10$ & 118 & 295 & 1 & 1 \\
\hline & $11-25$ & 113 & 14 & $3.628(2.632,5.001)$ & \\
\hline & $26-45$ & 23 & 58 & $6.304(3.718,10.690)$ & $2.495(0.981,6.344)$ \\
\hline \multirow{2}{*}{$\begin{array}{c}\text { Habit of physical } \\
\text { exercise }\end{array}$} & Yes & 52 & 171 & 1 & 1 \\
\hline & No & 288 & 260 & $3.643(2.560,5.183)$ & $0.715(0.434,1.177)$ \\
\hline \multirow{2}{*}{$\begin{array}{c}\text { Other paid } \\
\text { activities }\end{array}$} & Yes & 92 & 105 & 1 & 1 \\
\hline & No & 248 & 326 & $0.868(0.627,1.202)$ & $0.689(0.440,1.078)$ \\
\hline \multirow{3}{*}{$\begin{array}{c}\text { Work place social } \\
\text { environment }\end{array}$} & Poor & 165 & 39 & $17.707(11.198,27.997)$ & $6.799(3.79,12.297)$ \\
\hline & Fair & 121 & 166 & $3.051(2.090,4.453)$ & $1.753(1.060,2.897)$ \\
\hline & Good & 54 & 226 & 1 & 1 \\
\hline \multirow{2}{*}{ Job satisfaction } & Poor & 100 & 263 & $3.757(2.775,5.088)$ & $0.689(0.441,1.076)$ \\
\hline & Good & 240 & 168 & 1 & 1 \\
\hline \multirow{3}{*}{ Work posture } & Prolonged standing & 297 & 262 & 1 & 1 \\
\hline & Prolonged sitting & 34 & 106 & $0.283(0.186,0.431)$ & $0.237(0.139,0.404)$ \\
\hline & Others & 9 & 63 & $0.126(0.061,0.258)$ & $0.153(0.065,0.359)$ \\
\hline \multirow{2}{*}{$\begin{array}{l}\text { Enough teachers in } \\
\text { school }\end{array}$} & Yes & 64 & 288 & 1 & 1 \\
\hline & No & 276 & 143 & $8.685(6.195,12.176)$ & $3.786(2.420,5.922)$ \\
\hline \multirow{2}{*}{$\begin{array}{c}\text { Ergonomics } \\
\text { training }\end{array}$} & Yes & 39 & 106 & 1 & 1 \\
\hline & No & 301 & 263 & $4.930(3.352,7.250)$ & $2.246(1.345,3.750)$ \\
\hline \multirow{2}{*}{$\begin{array}{l}\text { Teaching aid } \\
\text { devices }\end{array}$} & Yes & 26 & 110 & 1 & 1 \\
\hline & No & 314 & 321 & $4.139(2.626,6.522)$ & $0.891(0.490,1.623)$ \\
\hline
\end{tabular}

Note: NB COR and AOR written in bold indicates statistical significance or P value $<0.05$

\section{Discussion}

This study disclosed the prevalence of low back pain and its associated risk factors of governmental primary school teachers in Addis Ababa, Ethiopia. The prevalence was 44\%. Age, sex, work place social environment, work posture, enough teachers in the school and ergonomic training were found to be associated with the occurrence of low back pain. The prevalence of LBP in our study
(44\%), was more of less similar with the same studies conducted in China (45.6\%) [19], Brazil (41.1\%) [3] and Malaysia (40.4\%) [2]. It also lays in the range of one-year prevalence of LBP among Africans (14\%-72\%) [6]. However, it is lower when compared to studies in Botswana and Gondar (57.5\%) and (55.7\%) respectively [15,10] and higher when compared to the global annual prevalence of back pain (31\%) [9]. In this study an increase in low back pain with age 
was observed. Teachers who were above 40 years were five times more likely to develop LBP when compared to those who were less than 30 years old [ AOR: 4.895, 95\% CI: $(2.215,10.820)]$.

Whereas, teachers in the age group of 31 to 40 years were two times more likely to develop LBP when compared to those who were less than 30 years old [ AOR: 1.960, 95\% CI: (1.119, 3.436)]. Similar association was revealed by other studies $[15,16]$. Workrelated links and increased risk for enduring diseases with age might influence the prevalence of LBP together with decline of healing ability. Degeneration in muscle mass and diminishing of cartilage between joints as the age advances could also contribute. Female teachers were 1.5 times more likely to develop LBP than male teachers [AOR=1.547, 95\%CI $(1.037,2.308)]$. Other studies also suggested that there is a positive association between female sex and LBP $[10,13,15,16,20]$. Though the main reason is not clear, it could be because of their life style variation and anatomical differences. The reason that males had shown to practice regular physical exercise than females could be another explanation even though habit of doing physical exercise didn't show a significant association with LBP in this study.

This study showed that work social environment is significant contributing factor to LBP. Those who had a poor and fair work social environment had about seven and two times increased risk of acquiring LBP [AOR: 6.799, 95\% CI $(3.79,12.297)]$ and [AOR: $1.753,95 \%$ CI $(1.06,2.897)]$ respectively than those who had a good environment. Similar results were revealed by other studies $[10,18]$. It has also been suggested that the more psychological demands needed for a particular task, the greater the possibility to develop any kind of musculoskeletal disorder regardless of the anatomical area [21]. Work posture and work load was found to be significantly associated with the occurrence of low back pain. Adopting Prolonged sitting and other positions (active, bending and twisting) had a lower risk of acquiring LBP by $76 \%$ and $85 \%$ when compared to those who adopt prolonged standing position [AOR: $0.23795 \% \mathrm{CI}(0.139,0.404)]$ and [AOR: 0.153, 95\%CI $(0.065,0.359)$ ] respectively. Those who were in a high work load had a four times risk of acquiring LBP than those who weren't [AOR: 3.786, 95\%CI $(2.420,5.922)]$.

Other studies also suggested that, prolonged sitting $[19,20]$ and static posture were positively associated with LBP while prolonged standing didn't show a significant association [19]. Back care ergonomics training was found to be significantly associated with the occurrence of LBP. Respondents who didn't have the training were two times more likely to develop LBP than those who did [AOR: 2.246, 95\% CI $(1.345,3.75)]$. Same results were found in Botswana and Hong Kong [12,18].

\section{Limitations of the Study}

Since the study is a cross sectional and self-reported, it might be subjected to exaggeration of some relation noted in this study and study subjects with LBP might be inclined to over report their psychosocial load. The recall period for the experience of LBP might be far or long ago therefore, it could have resulted in a misclassification due to recall bias. Though it is an important factor, we couldn't incorporate BMI as one of the dependent variables because of data incompleteness.

\section{Conclusion}

Our study revealed that low back pain is a thoughtful problem among governmental primary school teachers in Addis Ababa. Females have an increased risk of acquiring LBP than males. In addition, as age increases, the risk of developing LBP also significantly increases. Training on back care ergonomics, working posture, work social environment, and work load are also among the factors which showed a significant association with LBP and have to be given a great attention in order to surmount the situation.

\section{Acknowledgment}

We would like to express our deepest gratitude to Addis Ababa and Arada Sub-City Education Bureaus for their cooperation in facilitating the data collection activities. We would like to extend our appreciation to the data collectors and supervisors who participated in the study. We are also grateful to all study subjects who participated in the study and showed us their paramount sympathy in responding to the study questions.

\section{References}

1. Cieza A, Stucki G, Weigl M, Disler P, Jackel W, et al. (2004) ICF Core Sets for low back pain. Journal of rehabilitation medicine 36(0): 69-74.

2. Samad N, Abdullah H, Moin S, Tamrin S, Hashim Z (2010) Prevalence of low back pain and its risk factors among school teachers. American journal of applied sciences 7(5): 634 .

3. Lima M, Barros M, César C, Goldbaum M, Carandina L, et al. (2009) Impact of chronic disease on quality of life among the elderly in the state of São Paulo, Brazil: a population-based study. Revista Panamericana de Salud Pública 25(4): 314-321.

4. Lozano R, Naghavi M, Foreman K, Lim S, Shibuya K, et al. (2013) Global and regional mortality from 235 causes of death for 20 age groups in 1990 and 2010: a systematic analysis for the global burden of disease study 2010. The Lancet 380(9859): 2095-2128.

5. Skovron M (1992) Epidemiology of low back pain. Baillière's clinical rheumatology 6(3): 559-573.

6. Lim S, Vos T, Flaxman A, Danaei G, Shibuya K, et al. (2013) A comparative risk assessment of burden of disease and injury attributable to 67 risk factors and risk factor clusters in 21 regions, 1990-2010: a systematic analysis for the global burden of disease study 2010. The lancet 380(9859): 2224-2260.

7. Lidgren L (2003) The bone and joint decade 2000-2010. Bulletin of the World Health Organization. 81(9): 629.

8. Steenstra I, Verbeek J, Heymans M, Bongers P (2005) Prognostic factors for duration of sick leave in patients sick listed with acute low back pain: a systematic review of the literature. Occupational and environmental medicine 62(12): 851-860.

9. Hoy D, Bain C, Williams G, March L, Brooks P, et al. (2012) A systematic review of the global prevalence of low back pain. Arthritis \& Rheumatism 64(6): 2028-2037.

10. Beyen T, Mengestu M, Zele Y (2013) Low back pain and associated factors among teachers in Gondar Town, North Gondar, Amhara Region, Ethiopia. Occupational medicine \& health affairs 1(5).

11. Volinn E (1997) The Epidemiology of low back pain in the rest of the world: A review of surveys in low-and middle-income countries. Spine 22(15): 1747-1754. 
12. Sealetsa OJ, Thatcher A (2011) Ergonomics issues among sewing machine operators in the textile manufacturing industry in Botswana. Work: A journal of prevention, assessment and rehabilitation 38(3): 279-289.

13. Patience N, Derek R (2011) Systematic review of musculoskeletal disorders among school teachers. BMC musculoskeletal disorders 12 260.

14. Prüss Üstün A, Corvalán C (2007) How much disease burden can be prevented by environmental interventions? Epidemiology 18(1): 167178.

15. Patience N, Derek R (2014) Low back pain among school teachers in Botswana, prevalence and risk factors. BMC musculoskeletal disorders 15: 359.

16. Chaffin D, Park K (1973) A longitudinal study of low-back pain as associated with occupational weight lifting factors. The American industrial hygiene association journal 34(12): 513-525.

\section{ISSN: 2574-1241}

DOI: 10.26717/BJSTR.2018.10.001886

Tsega Ab Abebaw. Biomed J Sci \& Tech Res

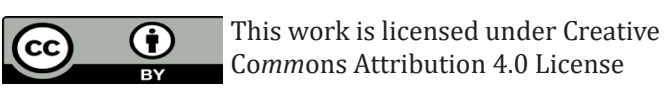

Submission Link: https://biomedres.us/submit-manuscript.php
17. Shiri R, Karppinen J, Leino Arjas P, Solovieva S, Viikari Juntura E (2010) The association between smoking and low back pain: a meta-analysis. The American journal of medicine 123(1): 87. e7- e35.

18. Bing Yip Y (2001) A study of work stress, patient handling activities and the risk of low back pain among nurses in Hong Kong. Journal of advanced nursing 36(6): 794-804.

19. Pengying Y, Fengying L, Liping L (2012) Neck/shoulder pain and low back pain among school teachers in China, prevalence and risk factors. BMC public health 12: 789.

20. Alem D, Ephrem M, Seblewengel L, Tilaye W (2015) Prevalence of low back pain and associated risk factors among Adama hospital medical college staff, Ethiopia. European journal of preventive medicine 3(6): 188-192.

21. Hestbaek L, Leboeuf Yde C, Kyvik K, Vach W, Russell M, et al. (2004) Comorbidity with low back pain: a cross-sectional population-based survey of 12- to 22-year-olds. Spine (Phila Pa 1976) 29(13): 1483-1491.

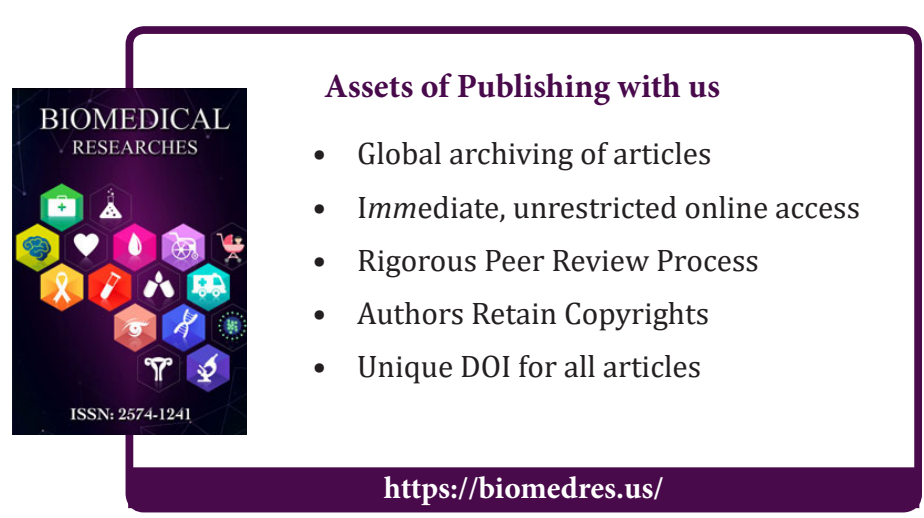

